Cad.Est.Ling., Campinas, 53(2): 125-136, Jul./Dez. 2011

\title{
O SENTIDO DAS CIDADES VIRTUAIS
}

\author{
CRISTIANE DIAS*
}

É sem dúvida, disse a mim mesma, que a cidade real (...) me interessa menos que a cidade sonhada, que a cidade fantasmada, que a cidade-tela, aquela que eu trago em mim $^{1}$ (Régine Robin).

\begin{abstract}
RESUMO: O presente artigo propõe uma reflexão sobre a linguagem informática, numérica, como mediadora das relações que se estabelecem entre o sujeito e os sentidos produzidos sobre cidade, num ambiente virtual. Para tanto, vou analisar uma montagem discursiva de imagens do percurso de um avatar no ambiente virtual do Second Life da favela de Heliópolis, na cidade de São Paulo e Cidade de Deus, no Rio de Janeiro. Essa análise tem como objetivo compreender como o discurso da cidade se textualiza na materialidade do mundo virtual, considerando, de um lado, a linguagem informática em sua forma visível e, de outro lado, a linguagem humana, em sua forma material.
\end{abstract}

Palavras-chave: cidade, linguagem, sentido

RÉSUMÉ: Cet article propose une réflexion sur le langage informatique, numérique, considerée comme celle qui fait la médiation entre le sujet et les sens produits sur la ville dans un univers virtuel. Pour cela, on va analyser une montage discursive d'images du parcours d'un avatar dans l'univers virtuel crée dans le jeu Second Life à partir du banlieu brésilien, Heliópolis, dans la ville de São Paulo et du banlieu Cidade de Deus, dans la ville de Rio de Janeiro. Cette analyse a comme but comprendre comment le discours de la ville se textualise dans la matérialité du monde virtuel, en considerant, d'un coté, le langage informatique dans sa forme visible et, d'autre coté, le langage humaine dans sa forme matériel.

Mots-clés: ville, langage, sens

\section{PARTIDA}

"Como definir um mundo virtual?" A partir desse questionamento, Philippe Quéau (1993) desenvolve sua reflexão sobre a linguagem do virtual. Para o autor, é preciso considerar que se trata de uma linguagem numérica, lógico-matemática. Por ser uma linguagem numérica, artificial, a linguagem do virtual não participa diretamente da cena a qual se refere para significá-la, uma vez que é pela algoritmização das imagens, das letras,

\footnotetext{
* Labeurb/Nudecri/Unicamp. Campinas/SP. <crisdias@unicamp.br>

${ }^{1}$ Tradução livre: “c'est sans doute, me suis-je dit, que la ville réelle (...) m'intéresse moins que la ville rêvée, que la ville fantasmée, que la ville-écran, celle que je porte en moi” (Régine Robin, 2009, p. 46).
} 
da voz, que essa linguagem se produz, sendo ela um mediador entre a situação e a formulação dessa situação no espaço virtual. Assim, cada letra do teclado é decodificada por um conjunto de 8 bits ou 1 byte, ou seja, combinações binárias de 0 e 1 . Por exemplo, o caractere "a" do teclado é codificado pelo octeto 0110 0001, a maiúscula "B” por 0100 0010, o sinal “+”" por 01001011 , e assim por diante.

É nesse aspecto da escrita informática que reside o que Herrenschmidt (2007) chama "transformações da escritura", porque a partir do código numérico, da linguagem informática, outra sistematicidade se cria, porque o modelo da escrita passa a ser o algoritmo, a combinação numérica; não é mais uma relação direta entre a situação e a escrita da situação. A relação do sujeito com a escrita, no computador, passa pelo cálculo, mesmo que ele não saiba ou não se dê conta disso. Para Herrenschmidt (2007, p. 405), a linguagem informática é

um conjunto, por definição, escrito, de caracteres, de números, de palavras e de regras, que permite reunir esses elementos para transcrever um algoritmo, escrever programas e dar instruções a um computador. Uma linguagem artificial, produzida conscientemente, para uma finalidade específica ${ }^{2}$ (...) (p. 405).

Sendo assim, para que um computador aja, é preciso vesti-lo, dotá-lo de linguagens e de métodos, e isso, hoje, já não é mais feito através da complicada linguagem máquina, como nos anos 40, 50. Hoje, existem "linguagens intérpretes" dessas linguagens máquina, que consistem num universo de "dialetos, formas específicas da linguagem fonte, e compõem uma imensa vegetação de gramáticas e de semânticas artificiais”3 (HERRENSCHMIDT, p. 406). Assim,

escrever informaticamente se funda sobre uma análise preconcebida do escrito, todo texto é o resultado de ações previstas antes pelo editor do logicial, o produto da máquina e, nisto, semelhante a um produto industrial na língua. (...) A língua é o objeto de contagem e de cálculos ${ }^{4}$ (Herrenschmidt 2007, p. 411).

Nessa perspectiva, como pensar os mundos virtuais, simulacros ${ }^{5}$ do mundo real, tendo o numérico como matéria da interpretação? Quéau (1993, p. 21) afirma que "Pitágoras, o primeiro filósofo da história, via no número a matéria e o molde do mundo. Para os pitagóricos, o número (arithmos) tinha o mesmo sentido que o verbo (logos)". O que está aí em questão é saber o que as formulações digitais podem nos fazer compreender do sentido do mundo, já que é delas que surgem os mundos virtuais. Que tipo de experiência

2 Tradução livre: "un ensemble, par définition écrit, de caracteres, de chiffres, de mots et de règles, qui permettent d'assembler ces éléments pour transcrire un algorithme, écrire des programmes et donner des instructions à un ordinateur. Un lagage artificiel, produit consciemment, dans un but précis (...)" (p. 405).

${ }^{3}$ Tradução livre: "dialectes, formes spécifiques du langage source, et composent une immense végétation de grammaires et de sémantiques artificielles" (p. 406).

${ }^{4}$ Tradução livre: "Écrire informatiquement se fonde sur une analyse préconçue de l'écrit, tout texte est le résultat d'actions prévues d'avance par l'éditeur du logiciel, le produit de la machine et, em cela, semblable à un produit industriel dans la langue. (...) La langue est l'objet de comptage et de calculs" (p. 411).

${ }^{5}$ Estou aqui falando de simulacro a partir da concepção de Herrenschmidt (2007, p. 420). Segundo essa autora, o simulacro é aquilo que, de virtual, passa a ter uma forma visível. 
do espaço o sujeito pode vir a ter nos mundos simulados, tais como o Second Life ${ }^{6}$ ? Mundo este já preconcebido pelo editor do logicial.

Interessa-me, aqui, refletir, mais especificamente, sobre o sentido das cidades virtuais ou digitais como lugares que se constituem pelas determinações que definem espaço, sujeito, vida, cidade (cf. ORLANDI, 2004, p. 11). Assim, como o sujeito se relaciona com as coisas, os outros sujeitos, o espaço, o urbano, nesses espaços simulados da cidade? Como o sujeito significa o já significado? Como ele escapa ao conjunto de ações que o logicial previamente determina e prevê que ele faça? Seriam esses espaços apenas cidades imaginárias, ou podemos aí nos deparar com o real da cidade? Poderíamos compreender os mundos virtuais como uma forma de "narratividade urbana", tal como definida por Orlandi (2004, p. 30)? Para a autora, a narratividade urbana é tomada como "palavras da cidade, parte da cena". Assim, que sentidos se constroem para cidade na textualidade virtual dos mundos simulados? Seriam esses mundos espaços apenas matemáticos, geométricos, numéricos ou seriam "espaços materiais, concretos funcionando como sítio de significação que requer gestos de interpretação particulares" (ORLANDI, 2004, p. 32)?

\section{REDES}

Com o surgimento da Internet, cuja dimensão geográfica das redes privilegia certa "invisibilidade" das relações sociais, políticas, econômicas, de poder, nos inquietamos com o burburinho dos fins. O fim do tempo, o fim do espaço, o fim das cidades, pois toda mudança em larga escala no mundo, as chamadas revoluções tecnológicas, como a da escrita, a da imprensa, a da moeda, a da informática, perturbam a ordem estabilizada das coisas que o sujeito procura sempre manter sob regimes os mais diversos.

Dessa forma, o surgimento da informática e, mais tarde, o da Internet, foi produzindo efeitos de sentido na vida do sujeito contemporâneo, pouco a pouco, ao mesmo tempo em que a globalização se consolidava sustentada pelo imaginário da interconexão planetária que a Internet tornaria possível com sua arquitetura em rede. A Internet é a materialização da instituição da ideia das redes pela informática. A noção de rede vai, portanto, significar o modo de organização das sociedades naquilo que concerne os modos e os meios dessa organização, mas também sua ordem $^{7}$. Desse modo, proponho que nos debrucemos um instante sobre a noção de rede significada pelas novas tecnologias de informação e comunicação, como uma "linguagem de concepção da cidade" (MAGERAND e MORTAMAIS), no que se refere à sua organização, ao empírico da cidade. Segundo Magerand e Mortamais (2003, p. 207), "os novos instrumentos tecnológicos que se inscrevem em aplicações extremamente diversas vão ter repercussões sobre nossos modos

${ }^{6}$ O Second Life é um ambiente online, virtual 3D, criado pela empresa Linden Lab (San Francisco). O Second Life é um mundo online no qual os residentes criam representações virtuais de si mesmos, conhecidas como avatares, e se relacionam com outros avatares, lugares ou objetos. Pode ser considerado um jogo ou uma rede social. <http://eletronicos.hsw.uol.com.br/second-life.htm>

${ }^{7}$ Estou aqui levando em consideração a relação proposta por Orlandi (2004, p. 35) entre ordem e organização. Para a autora, a ordem "é do domínio do simbólico na relação como o real da história (a sistematicidade sujeita a equívoco) articulação necessária e contraditória entre estrutura e acontecimento, enquanto a organização refere ao empírico e ao imaginário (o arranjo das unidades). 


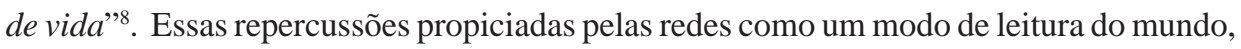
da ordem do mundo, já fazem parte do cotidiano de muitos sujeitos e colocam mesmo em "desuso", em questão, outras redes que constituem a cidade, como as redes de água, de energia, redes de trocas humanas, de pedestres, redes institucionais, econômicas, redes de transporte, redes de supermercados, de lojas, de construções urbanas. Conforme nos mostram Magerand e Mortamais (2003), essas redes e sub-redes "acumuladas há séculos" podem ser, hoje, qualificadas de redes tradicionais. A elas se acrescentam as redes informáticas, que vão engendrar novas configurações urbanas. Um exemplo dessas novas configurações que modificam as redes tradicionais é que, sem sair de casa, com a Internet, um sujeito pode ter acesso à informação, fazer compras, consultar livros na biblioteca ou numa livraria, fazer cadastro numa agência de emprego, comprar ingressos para ir ao cinema, e muitas outras coisas. Assim, as redes tradicionais se modificam em função da rede Internet, que a elas se combinam, produzindo outros modos de viver a cidade, o espaço urbano. A própria relação com o trabalho (espaço de trabalho) se modifica em função da arquitetura das redes.

Nessa perspectiva, as cidades contemporâneas mudam não somente no que diz respeito às práticas (ideológicas) dos sujeitos, mas também no que diz respeito à infraestrutura.

Vejamos alguns elementos da noção de cidade digital trazida por Lemos, no "Guia das Cidade Digitais",

\begin{abstract}
Hoje, em pleno século XXI, as novas tecnologias de comunicação e informação imprimem novas marcas ao urbano. As cidades digitais são as cidades da globalização, onde as redes telemáticas fazem parte da vida quotidiana e constituem-se como a infra-estrutura básica e hegemônica da época.
\end{abstract}

De acordo com essa afirmação, o conceito de cidade digital significa a partir da discursividade da globalização, produzindo um efeito de homogeneidade, consenso, organização. Ainda segundo Lemos, o termo cidade digital teve sua origem para designar projetos governamentais, privados e/ou da sociedade civil que visam criar uma representação na web de um determinado lugar. Cidade Digital é aqui um portal com informações gerais e serviços, comunidades virtuais e representação política sobre uma determinada área urbana.

Além dessa acepção "original", o autor aponta três outros "tipos de experiências que relacionam cidades e novas tecnologias de comunicação", são eles:

$\sqrt{ }$ a criação de infra-estrutura, serviços e acesso público em uma determinada área urbana para o uso das novas tecnologias e redes telemáticas. O objetivo é criar interfaces entre o espaço eletrônico e o espaço físico através de oferecimento de teleportos, telecentros, quiosques multimídia e áreas de acesso e serviços.

$\sqrt{ }$ modelagens 3D a partir de Sistemas de Informação Espacial (SIS, spacial information system e GIS, geographic information system) para criação de simulação de espaços

\footnotetext{
${ }^{8}$ Tradução livre: "Les nouveaux outils technologiques qui s'inscrivent dans des applications extrêmement diverses vont avoir des répercutions sur nos modes de vie" (Magerand e Mortamais, 2003, p. 207).

${ }^{9}$ http://www.guiadascidadesdigitais.com.br/site/pagina/o-que-cidade-digital. Acesso em 25 ago 2011.
} 
urbanos. Esses modelos são chamados de “CyberCity SIS” e são sistemas informatizados utilizados para visualizar e processar dados espaciais de cidades. As simulações ajudam no planejamento e gestão do espaço, servindo como instrumento estratégico do urbanismo contemporâneo.

$\sqrt{ }$ A quarta categoria, que podemos chamar de "metafórica", é formada por projetos que não representam um espaço urbano real. Estes projetos são chamados por alguns autores de "non-grounded cybercities", cidades não enraizadas em espaços urbanos reais. Essas Cidades Digitais são sites que criam comunidades virtuais (fóruns, chats, news, etc.) utilizando a metáfora de uma cidade para a organização do acesso e da navegação pelas informações. Nesse caso, não há uma cidade real, como por exemplo "Twin Worlds", "V-Chat", "DigitalEE" ou o popular "Second Life".

Seria possível, a partir dessas categorias, considerar o real da cidade? Qual a forma material da relação cidade e novas tecnologias que está em funcionamento no conceito de cidade digital, nas diferentes categorias apresentadas por Lemos? Não estou aqui interessada na cidade real, mas no real da cidade, naquilo que da cidade não pode ser algoritmizado, preestabelecido por programas de computador, e que emerge pelas condições de produção e pela memória discursiva do sujeito que utiliza o programa. É nessa instância que a forma material é fundamental, enquanto "acontecimento do significante (estrutura) no sujeito, no mundo" (ORLANDI, 2001, p. 40).

Em nosso entender, o conceito de cidade digital trazido nas categorizações anteriores, coloca a cidade e o urbano como já significados pela tecnologia, não deixando margem para o trabalho com o processo pelo qual a relação cidade e tecnologia constitui o sujeito contemporâneo. Trata-se de estrutura, mas não do acontecimento. Assim, nossa questão é: o que seriam cidades metafóricas numa perspectiva discursiva da cidade digital?

Para a Análise de Discurso, a noção de efeito metafórico é fundamental. Trata-se de considerarmos o "deslizamento de sentido" (PECHEUX, 2010, p. 96) nas formulações, de modo a compreendermos através da historicidade, as filiações de sentidos que fazem com que duas (ou mais) formulações diferentes, sejam "semanticamente equivalentes". Desse modo, cidades metafóricas, podem ser compreendidas em seu processo de produção de sentidos, uma vez que fazem deslizar sentidos da cidade "real". Um desses sentidos é o de território para rede. Ao falarmos em território, estamos nos referindo a territórios centralizados, onde há concentrações humanas, dos quais as grandes cidades são o exemplo. Quando falamos em rede, estamos nos referindo a redes descentralizadas, que ligam entre si nós, por entre os quais as informações circulam. Ora, se, de um lado, o do território, falamos em concentração de sujeitos; de outro, o da rede, falamos em circulação de informação.

São dois modos distintos de significar as relações sociais, de poder, econômicas, que regem as cidades, com processos de produção de sentidos distintos. Ambos, porém, determinados pelo discurso da globalização, sua condição de produção. Assim, as cidades digitais, sejam elas portais de informação, modelagens 3D, infraestrutura ou metáforas, elas se apoiam "na tensa contradição entre, de um lado, a expectativa de uma democracia 
planetária ilusória e, de outro, a prática de uma real economia ditatorial. O "político" aparece nessa conjuntura como argumento" (ORLANDI, 2011, p. 5).

As cidades digitais, tais como comumente descritas, são espaços com sentidos estabilizados, empíricos, imaginários, onde o político fica apagado em prol do consenso. Esse discurso da organização, do planejamento, está textualizado em qualquer das quatro categorias apresentadas por Lemos. É fato que a organização faz parte da constituição da cidade, no que diz respeito aos seus trajetos, vias, porém, conforme nos ensina Orlandi (2004, p. 63), do ponto de vista simbólico, "organização e desorganização se acompanham".

Desse ponto de vista, nas cidades digitais, não há espaço para a falha, a falta, o conflito, a resistência, o inesperado. Isso tem a ver com a própria linguagem máquina, artificial, da qual tratei no início desse artigo, com sua lógica binária sim/não. Como lembra Herrenschmidt (2007, p. 408), no computador, aceitamos que a atividade material de escrever tenha sido reduzida a operações mínimas, codificadas sob forma binária.

No entanto, é preciso lembrar que o sujeito escapa. Daí a noção de "entremeio" ser tão importante, pois é no entremeio que é possível escapar ao modo de significação da lógica disjuntiva sim ou não e produzir sentidos outros, não previstos ou codificados pelo programa. Sentidos que se constituem no percurso, no entre da linguagem intérprete, a da máquina, e a linguagem humana, onde a cidade se materializa, em seu real, havendo lugar para a interpretação, e onde podemos pensar nos seus gestos.

\section{PERCURSO}

Nesse momento, convido o leitor a acompanhar o percurso de um avatar no Second Life, através do recorte de imagens desse percurso. As imagens foram selecionadas por mim, como o objetivo de compreendermos os gestos de interpretação, o modo de significar a cidade que está textualizado na própria elaboração do jogo simulador, ou seja, pela escrita artificial da cidade que o jogo propõe ao leitor, através da textualização da cidade no ambiente virtual. O que da cidade é reproduzido no ambiente virtual e o que fica de fora? Que sentidos da cidade o jogo formula?

A partir de uma montagem de imagens, o leitor irá acompanhar o percurso do avatar pelo ambiente virtual da favela de Heliópolis ${ }^{10}$, em São Paulo, e Cidade de Deus ${ }^{11}$, no Rio de Janeiro.

\footnotetext{
${ }^{10}$ Bairro situado na zona sul de São Paulo/Brasil e é uma das maiores favelas do mundo com mais de 120 mil habitantes.

${ }^{11}$ Bairro situado na Zona Oeste da cidade do Rio de Janeiro. Foi construído em 1960 pelo governo do então Estado da Guanabara, como parte da política de remoção de favelas de outras áreas da cidade.
} 
Cadernos de Estudos Lingüisticos, Campinas, 53(2), Jul./Dez. 2011 HELIÓPOLIS

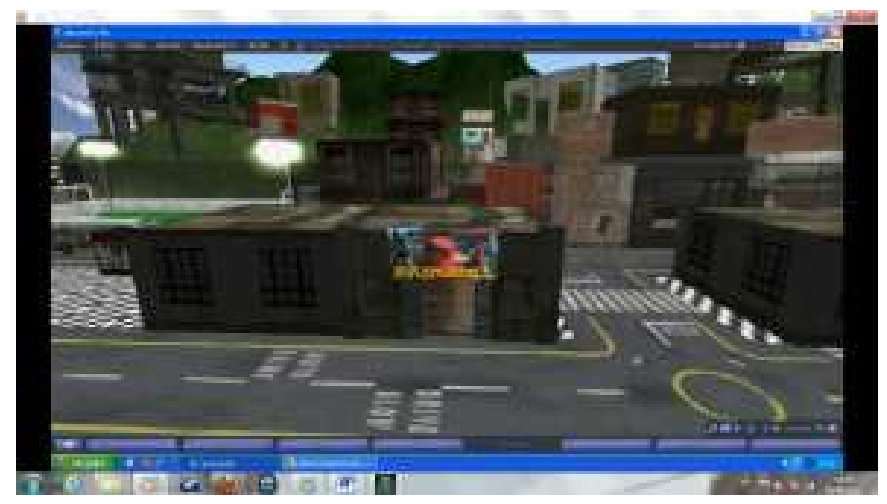

Imagem 1

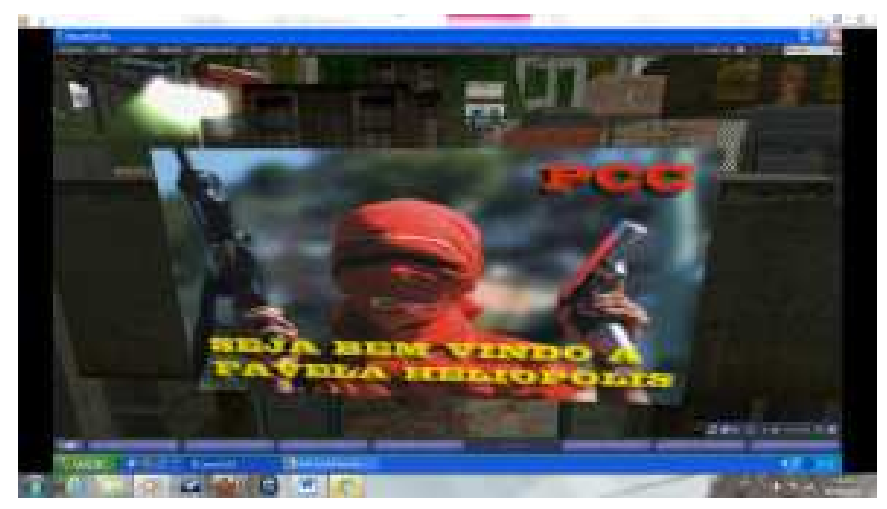

Imagem 2

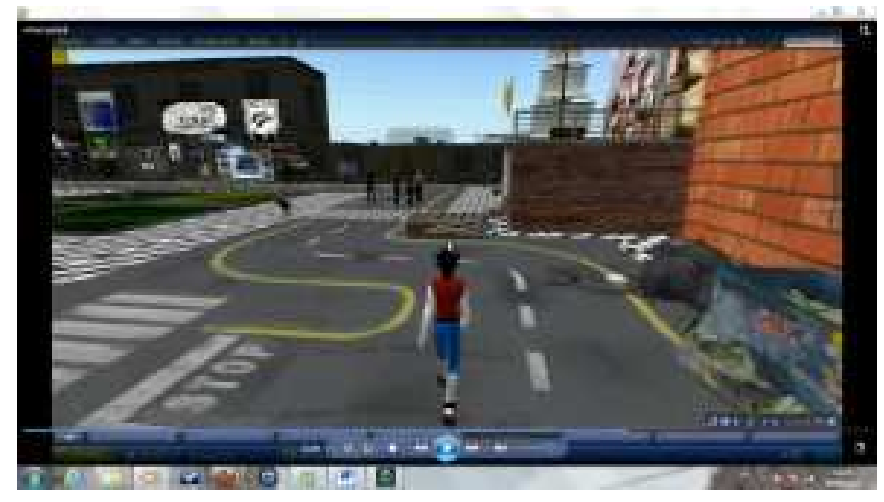

Imagem 3 


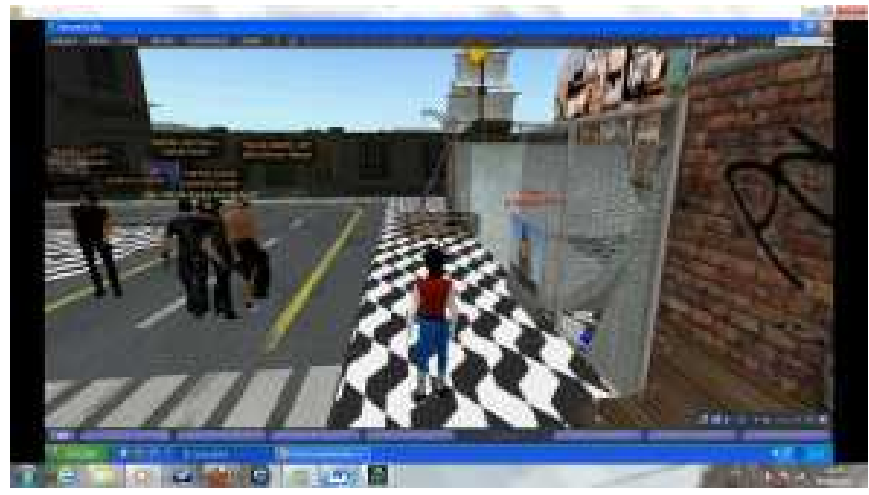

Imagem 4

\section{CIDADE DE DEUS}

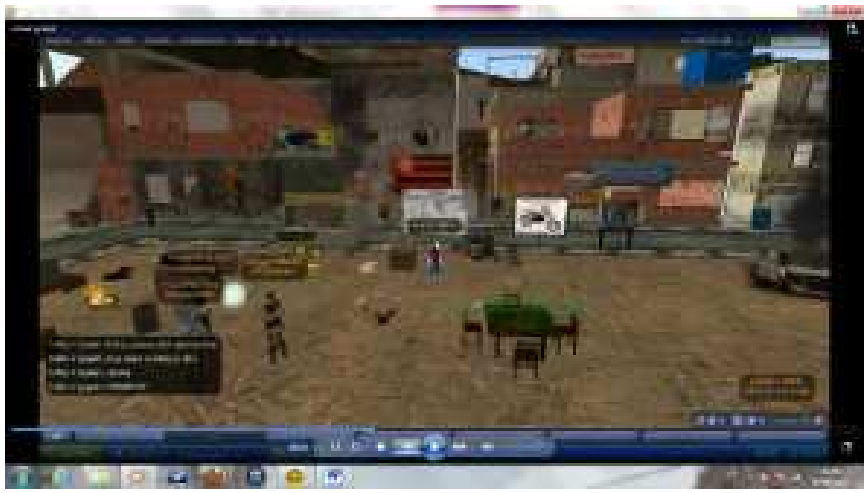

Imagem 5

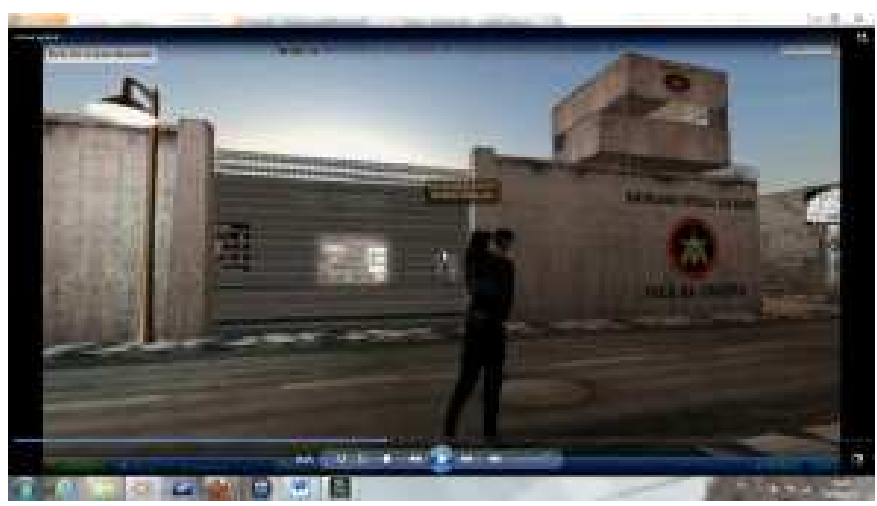

Imagem 6 


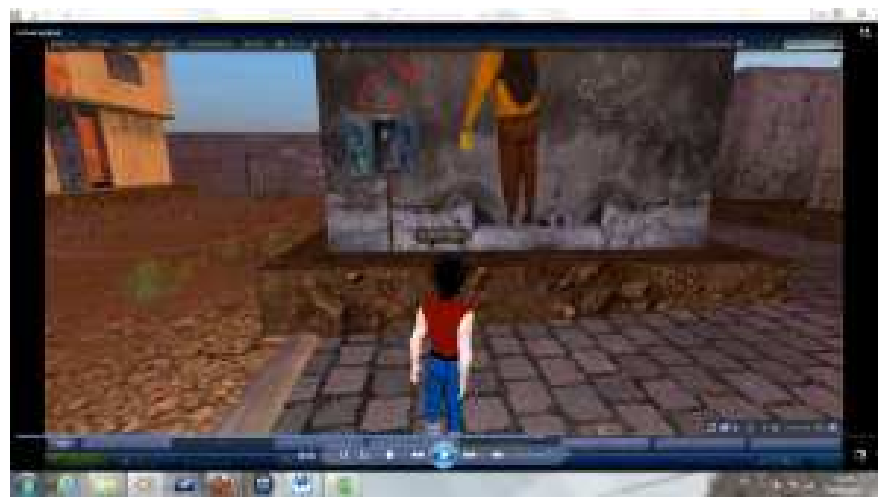

Imagem 7

Gostaria de chamar a atenção, nessas imagens, para o sentido da violência e da criminalidade que estão significando, no Second Life, essas duas favelas de duas grandes cidades brasileiras: São Paulo e Rio de Janeiro. Os sentidos que aí circulam são os do senso comum, os do consenso sobre o que é uma favela no Brasil. O "simulador da vida real" formula esses sentidos como os únicos possíveis e como aqueles que "representam"/ "reproduzem" o real da vida nesses lugares, não deixando margem para que outros sentidos se construam no percurso do sujeito-avatar.

Destaquemos alguns elementos para a análise. Na imagem 1 e, em seguida, no zoom (imagem 2), é o $\mathrm{PCC}^{12}$, armado, que dá as boas vindas ao sujeito que visita o ambiente virtual de Heliópolis/SP, por meio de seu avatar. A imagem do homem encapuzado produz o sentido do criminoso, do crime e da violência. A assinatura do PCC, considerada uma organização criminosa da cidade de São Paulo, já produz sentidos em certa direção, antecipando, pelo trabalho da memória discursiva, o que o sujeito vai encontrar naquele ambiente. É o PCC que recebe os visitantes, legitimando o discurso da criminalidade na textualidade do jogo.

Já no interior da favela, o avatar passa por um homem morto, esquartejado, jogado ao lado dos sacos de lixo (imagem 3), enquanto se aproxima de um grupo de homens armados (imagem 4). A cena do homem esquartejado ao lado dos sacos de lixo já produz uma indistinção entre o lixo e o humano, nas condições de produção da vida da favela. Os sentidos da imagem tem como memória discursiva o esquartejamento de um integrante do Terceiro Comando Puro $\left(\mathrm{TCP}^{13}\right)$, por um integrante do Comando Vermelho $\left(\mathrm{CV}^{14}\right)$, que disputavam o controle de vendas de drogas no Morro da Serrinha, em Madureira, na Zona Norte do Rio. O fato ocorreu no início de novembro de 2010.

${ }^{12}$ Primeiro Comando da Capital (PCC) é uma organização criminosa paulistana, criada com o objetivo manifesto de "defender" os direitos de pessoas encarceradas no país.

${ }^{13}$ Principal grupo rival do Comando Vermelho. "Surgiu a partir de luta por poder entre os líderes do CV em meados da década de 1980”. <http://pt.wikipedia.org/wiki/Comando_Vermelho>

${ }^{14}$ Facção criminosa do Estado do Rio de Janeiro. 


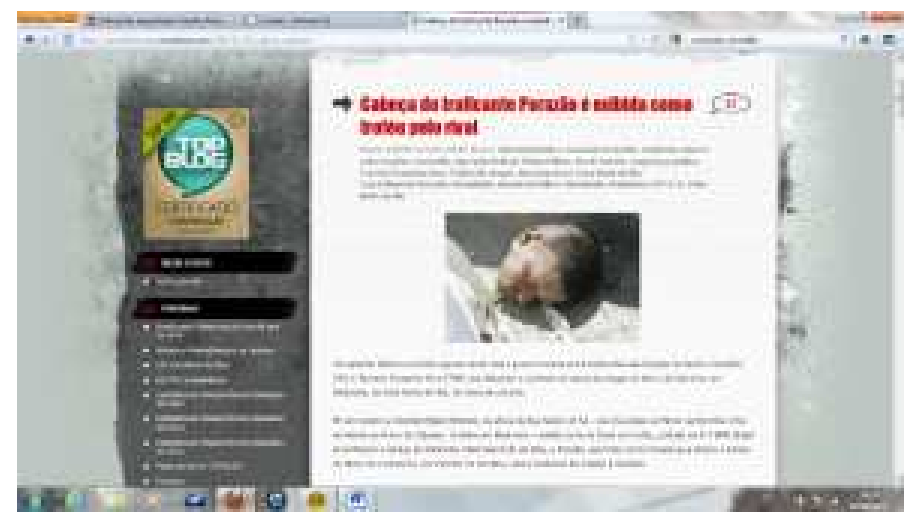

http://robertatrindade.wordpress.com/2010/11/05/cabeca-parazao/

O que interessa destacar nessa sequência de imagens apresentada é o fato de que o simulador lida com sentidos já significados, no caso desse acontecimento do homem esquartejado, significado pela mídia, pelo consenso que se produz na sociedade sobre a vida na favela, sobre a indistinção homem-lixo, sobre a lei do mais forte. Ou seja, o simulador trabalha com estereótipos que naturalizam o sentido da violência e da criminalidade nas favelas.

É com esses mesmos sentidos que as três imagens selecionadas para mostrar o percurso do sujeito-avatar pela Cidade de Deus/RJ trabalham. Na imagem 6 aparece o BOPE, Batalhão de Operações Policiais Especiais do Rio de Janeiro, que, segundo o site oficial ${ }^{15}$, é composto por "policiais especializados em operações de combate ao crime em área de alto risco e resgate de reféns". Ora, a presença do BOPE na entrada da Cidade de Deus produz o sentido do conflito armado entre polícia e traficantes e já significa o ambiente da favela Cidade de Deus como "área de risco". Sentidos esses largamente explorados e reiterados no filme Tropa de Elite (2007), de José Padilha e que fazem parte da memória discursiva do brasileiro sobre a Cidade de Deus, como um sentido cristalizado da violência.

Além disso, na imagem 7, temos, mais uma vez, a assinatura de uma organização criminosa, dessa vez, do CV, que é uma organização criminosa do Rio de Janeiro. A assinatura aparece pichada na parede, ao lado da formulação "quem sabe é nóis". Essas assinaturas produzem o sentido do controle da vida nessas favelas, pelas organizações PCC, em São Paulo, que dá as boas vindas aos visitantes, e pelo CV, no Rio de Janeiro, que diz quem é que sabe, quem é que manda. E o BOPE, no meio delas.

Assim, a violência urbana, a criminalidade, a guerra entre polícia e bandido, são os sentidos com os quais o ambiente virtual dessas duas favelas, uma de São Paulo e outra do Rio de Janeiro, significam essas cidades e as textualizam. São esses os sentidos que o jogo simula, evidencia, e que, pelo simulacro, torna visível (forma visível). Com isso, a forma visível (produto) se sobrepõe à forma material (processo), na produção de sentidos sobre/ da cidade.

\footnotetext{
${ }^{15} \mathrm{http}: / / w w w . b o p e r j . o r g /$
} 


\section{CHEGADA}

Se considerarmos que ao construir seus trajetos, seus percursos, o sujeito se constitui neles, ao construir sentidos para suas experiências, cabe perguntar, que tipo de experiência o ambiente virtual propicia, levando em consideração os sentidos colocados em jogo na formulação do ambiente virtual das duas favelas das cidades do Rio de Janeiro e São Paulo? Será que o sujeito é determinado pelos sentidos do(em) jogo ou ele escapa, se depara com o real?

Dubey $(2001$, p. 17, 18), alerta para o perigo e o absurdo de procurar na tecnologia uma resposta a questões políticas e éticas. Há o que este autor chama de uma confusão crescente entre os mundos virtuais e o mundo da vida. $\mathrm{O}$ autor continua questionando: " $a$ transparência da rede não é um álibi à dissimulação de poderes mais e mais difíceis de localizar, orientando-nos para um totalitarismo high tech? ${ }^{16 "}$

É fato que a tecnologia provoca um estado de incerteza e nos cabe interrogar a visão de um mundo sem outra alteridade que aquela autorizada pelo modelo tecnológico e conforme a sua linguagem.

Conforme aponta Dubey (2001, p. 21-22)

fora dos limites que nos determinam enquanto seres vivos, nada se opõe ao fato de que um mundo radicalmente novo emerge do poder de cálculo dos computadores. [lá] tudo, ou quase tudo, se torna possível: voar, visitar extensões longínquas ou imaginárias, brincar com moléculas, passear nos maiores museus do mundo (...). Mas já que se trata de "quase tudo", o que acontece com o resto, desta quantidade negligenciável fora do domínio do cálculo que só nos interessa aqui, este "quase nada" do qual a vida é suspensa como um fio? ${ }^{17}$

Assim, é esse resto que é da ordem da exterioridade do ambiente virtual, esse resto que não se pode simular, calcular, algoritmizar, que não é da ordem do imaginário, mas do simbólico, já que o sujeito é histórico e simbólico, que produz o corte que ao contrário de suspender a vida, produz rupturas na ordem das coisas-a-saber (PECHEUX 2008) e conduz o sujeito por outros percursos ainda não imaginados.

\section{REFERÊNCIAS BIBLIOGRÁFICAS}

DUBEY, Gérard. (2001). Le lien social à l’ère du virtuel. Paris: PUF.

HERRENSCHMIDT, Clarisse. (2007). Les trois écritures: langue, nombre, code. Paris: Éditions Gallimard.

\footnotetext{
${ }^{16}$ Tradução livre: “Le soi-disant transparence du réseau n'est-elle pas qu'um álibi à la dissimulation de pouvoirs de plus em plus difficiles dans les faits à localiser, et ne s'oriente-t-on pas au final vers une forme de totalitarisme high tech?" (p. 17).

${ }^{17}$ Tradução livre: “Hors des limites qui nous déterminent en tant qu'êtres vivants, rien ne s'oppose à ce qu'un monde radicalement nouveau émerge de la puissence de calcul des ordinateurs. [...] tout, ou presque tout, devienne possible: voler, visiter des contrées lointaines ou imaginaires, jouer avec des molécules, se promener dans le plus grand musée du monde (...). Mais puisqu'il s'agit de "presque tout", qu'advient-il du reste, de cette quantité négligeable hors du domaine du calcul qui seul nous interesse ici, de ce "presque rien" auquel 1 avie est suspendue comme à um fil?"' (p. 21-22).
} 
ORLANDI, Eni. (2011). Língua, comunidade e relações sociais no espaço digital. In: DIAS, Cristiane (org.) $e$ Urbano: sentidos do espaço urbano/digital. Campinas: Labeurb < http://www.labeurb.unicamp.br/ $\underline{\text { livroEurbano/>. Acesso em } 29 \text { ago } 2011 .}$

LEMOS, André. O que é cidade digital? In. Guia das cidades digitais. < $\underline{\text { http:// }}$ www.guiadascidadesdigitais.com.br/site/pagina/o-que-cidade-digital.> Acesso em 25 ago 2011

MAGERAND, Jean; MORTAMAIS, Elizabeth. (2003). Vers la cité hypermédiate: du modernisme-fossile à l'hypercité-immédiate. Paris: L'Harmattan.

ORLANDI, Eni. (2004). Cidade dos sentidos. Campinas: Pontes.

ORLANDI, Eni. (2001). Discurso e texto. Campinas: Pontes.

PECHEUX, Michel. (2010). Análise automática do discurso (AAD69). In. GADET, F. e HAK, T. (orgs.) Por uma análise automática do discurso. Trad. Bethania Mariani et al. Campinas: Editora da Unicamp.

PECHEUX, Michel. (2008). O discurso, estrutura ou acontecimento. Trad. Eni Orlandi. 5 ed. Pontes.

QUÉAU, Philippe. (1995). Lo virtual: virtudes y vértigos. Trad. Patrick Ducher. Barcelona-Buenos AiresMéxico: Paidós.

ROBIN, Régine. (2009). Mégapolis: les derniers pas du flâneur. Paris: Stock. 